\title{
Performance of Underfloor Air Distribution in a Field Setting
}

\author{
W.J. Fisk ${ }^{1}$, D. Faulkner ${ }^{1}$, D.P. Sullivan ${ }^{1}$, C. Chao ${ }^{2}$, \\ M. P. Wan ${ }^{2}$, L. Zagreus ${ }^{3}$, T. Webster ${ }^{3}$ \\ ${ }^{1}$ Indoor Environment Department \\ Environmental Energy Technologies Division \\ Lawrence Berkeley National Laboratory \\ Berkeley, CA \\ ${ }^{2}$ Department of Mechanical Engineering \\ Hong Kong University of Science and Technology \\ Hong Kong \\ ${ }^{3}$ Center for the Built Environment \\ University of California, Berkeley \\ Berkeley, CA
}

This work was supported by the Assistant Secretary for Energy Efficiency and Renewable Energy, Building Technologies Program of the U.S. Department of Energy under contract DEAC03-76SF00098 


\title{
Performance of Underfloor Air Distribution in a Field Setting
}

\author{
W.J. Fisk ${ }^{1}$, D. Faulkner ${ }^{1}$, and D.P. Sullivan ${ }^{1}$, C. Chao $^{2}$ and M. P. Wan ${ }^{2}$, L. Zagreus $^{3}$, T. Webster ${ }^{3}$ \\ ${ }^{1}$ Indoor Environment Department, Lawrence Berkeley National Laboratory, Berkeley, CA \\ ${ }^{2}$ Department of Mechanical Engineering, Hong Kong University of Science and Technology, Hong Kong \\ ${ }^{3}$ Center for the Built Environment, University of California, Berkeley, CA
}

\begin{abstract}
Underfloor air distribution (UFAD) is a new method of supplying heated or cooled air throughout a building. Reported advantages of UFAD include energy savings and improved indoor air quality (IAQ). We measured several aspects of the performance of an UFAD system installed in a medium-size office building. The measured air change effectiveness was very close to unity, which is comparable to that measured in buildings with typical overhead air distribution. The pollutant removal efficiency for carbon dioxide was $13 \%$ higher than expected in a space with well-mixed air, suggesting a 13\% reduction in exposures to occupant generated pollutants. The increase in indoor air temperatures with height above the floor was only 1 to $2{ }^{\circ} \mathrm{C}$. This amount of thermal stratification could reduce the sensible energy requirements for cooling of outdoor air by approximately $10 \%$. The occupant's level of satisfaction with thermal conditions was well above average and this high satisfaction rating could possibly be due, in all or part, to the use of a UFAD system. The results of this study provide some evidence of moderate energy and IAQ-related benefits of UFAD. Before general conclusions are drawn, the benefits need to be confirmed in other studies.
\end{abstract}

Key words: air distribution, energy, pollutant removal, survey, underfloor, ventilation efficiency

\section{BACKGROUND}

Underfloor air distribution (UFAD), described in detail by Bauman (2003), is a relatively new method of supplying heated or cooled air throughout a building. With UFAD, conditioned air, normally a mixture of recirculated and outdoor air, is supplied to a plenum located below a raised floor. Air enters the occupied spaces via supply air diffusers inserted at desired locations in the raised floor. For a number of reasons (Lehrer and Bauman 2003, Fisk et al. 2004), the use of UFAD is increasing rapidly. Potential energy savings are one motivation for UFAD. Because UFAD systems can supply higher temperature air ${ }^{1}$ than conventional HVAC systems, UFAD increases the opportunity to use outdoor air for free cooling via economizer systems under

${ }^{1}$ UFAD supply air temperatures are typically greater than $17{ }^{\circ} \mathrm{C}$. In conventional overhead air distribution systems, supply air temperatures are typically $13-16$ ${ }^{\circ} \mathrm{C}$. suitable climatic conditions. Example calculations for a building in San Francisco indicate that there are 2200 additional hours of free cooling per year via an economizer with UFAD versus conventional air distribution (Lehrer and Bauman 2003). The increased supply air temperature can also improve the coefficient of performance of air conditioning systems. Based primarily on laboratory studies, UFAD can also result in a vertical thermal gradient in air temperature within the occupied spaces. As discussed subsequently, the vertical temperature gradient can reduce the energy required for air conditioning.

An upward displacement ventilation airflow pattern leading to an improvement in ventilation efficiency is another widely reported advantage of UFAD. An index often used to quantify the degree of improvement of ventilation efficiency (ASHRAE 2002) is the air change effectiveness (ACE). The practical interpretation is that the 
ACE indicates the effective ventilation rate at the breathing zone divided by the ventilation rate that would occur throughout the indoor space with the same amount of outdoor air supply and perfect mixing of the indoor air. If the ACE is greater than unity, the minimum required rate of outdoor air supply can be reduced (multiplied by 1/ACE) to save energy (ASHRAE 2002). For example, with an ACE of 1.5, the required minimum rate of outside air supply is reduced by one third. At present, there are very few published data on the values of ventilation efficiency obtained with UFAD systems. Our prior laboratory studies demonstrated that one first-generation UFAD system produced ACE values as high as 1.3 under some operating conditions (Faulkner et al. 1993). A primary objective of this study was to determine whether UFAD in practice results in a ventilation efficiency above unity. Secondary objectives of this study were to add to the limited information on the thermal stratification, occupant satisfaction with thermal conditions, and occupant satisfaction with air quality in buildings with UFAD.

\section{STUDY METHODS}

\subsection{Study building}

The measurements were performed in a two-story office building with a floor area of 3,100 $\mathrm{m}^{2}$. The building, located in Pennsylvania, has high levels of thermal insulation, high performance triplepane windows, and a window configuration plus light shelves designed to provide a high level of daylight. The second floor, which contained most of our study sites, has a ceiling height that ranged from $2.9 \mathrm{~m}$ at the building perimeter to a maximum of $6.1 \mathrm{~m}$. The first floor ceiling height was $2.5 \mathrm{~m}$. The building has two mechanical rooms holding HVAC equipment that serve the east and west wings of the building, respectively. Each mechanical room has a supply of outdoor air from a roof-mounted air-to-air heat exchanger. Preheated or pre-cooled outdoor air from the heat exchangers is mixed with multiple airstreams of recirculated indoor air, thermally conditioned with ground-source heat pump units, and then supplied to the underfloor air supply plenums of the UFAD system. The conditioned air enters the occupied spaces of the building through air supply diffusers installed in the suspended floor. The supply diffusers are swirl diffusers that cause the exiting air to swirl about a vertical axis. Air exits the occupied spaces through return grilles located 2.7 to $3.0 \mathrm{~m}$ above the floor in the ceiling or walls. Indoor temperature is maintained by cycling the operation of the ground source heat pumps that heat or cool the supply airstreams. The flow rates of outdoor and recirculated air are maintained constant. Based on design data, supply air flow rates were 2.1 to $4.0 \mathrm{~L} / \mathrm{s}$ per square meter of floor area and overall, the estimated internal heat generation rate was 16 to $20 \mathrm{~W} / \mathrm{m}^{2}$.

\subsection{Air change effectiveness (ACE) measurement}

The ACE is a metric for ventilation efficiency and was determined from measured values of age of air, where the age of a parcel of air represents the average time elapsed since the molecules in that parcel entered the building. In general, air that has been in the building for a longer time is likely to contain more indoor-generated air pollutants. While there is no rigorous definition of a local ventilation rate, the reciprocal of an age of air measured at a location can be informally considered as a local ventilation rate. Typically, age of air is expressed with units of hours, and its reciprocal then has units of $\mathrm{hr}^{-1}$.

We measured ACE using the tracer gas stepup procedure with a measurement protocol similar to that defined in the ASHRAE measurement standard for ACE (ASHRAE 2002). To initiate tracer stepup measurements, we started sulfur hexafluoride $\left(\mathrm{SF}_{6}\right)$ tracer gas injection into the two streams of incoming outdoor air using speedcontrolled peristaltic pumps that drew $\mathrm{SF}_{6}$ from gas storage bags. The $\mathrm{SF}_{6}$ was injected upstream of the outdoor air supply fans which aided mixing of $\mathrm{SF}_{6}$ within the outdoor airstreams. The injection rates were maintained constant at rates that produced the same $\mathrm{SF}_{6}$ concentration, within $5 \%$, in each stream of outdoor air. $\mathrm{SF}_{6}$ gas concentrations were measured versus time in exhaust airstreams, at return grilles, and at representative breathing-level locations in the occupied space. After a few hours elapsed, indoor $\mathrm{SF}_{6}$ concentrations stabilized and the injection 
process and measurements were terminated. At each measurement location, the age of air was calculated using the equation

$$
A_{i}=\int_{0}^{\infty}\left(1-\frac{C_{i}(t)}{C_{\infty}(t)}\right) d t
$$

where $A_{i}$ is the age of air at location $i, C$ is the tracer gas concentration, $t$ is the time elapsed since the start of tracer gas injection, and $C_{\infty}$ is the steady state tracer gas concentration. In practice, the integral was evaluated numerically for the time period when tracer gas concentrations increased, which was approximately four hours. The ACE was calculated from the equation

$\mathrm{ACE}=\tau_{\mathrm{n}} / \mathrm{A}_{\mathrm{avg}}$

where $\tau_{\mathrm{n}}$ is the nominal ventilation time constant and $A_{\text {avg }}$ is the average age of air measured at the breathing level locations. The nominal time constant is the average age of air in airstreams exhausted from the building and equals the age of air that would occur throughout the building if the indoor air were perfectly mixed. Because we were most interested in the ACE in the regions of the building where people spend most time, we also calculated local values of ACE, substituting the age of air at a return air grille for $\tau_{n}$, and replacing $A_{\text {avg }}$ with the age of air at a nearby the seated or standing breathing-level measurement location.

We measured tracer gas concentrations as a function of time at four sites per test in the occupied spaces, in each exhaust airstream, and in each stream of incoming outdoor air. Some measurement sites changed between tests. In the occupied spaces, two measurement sites were private offices and four measurement sites were at cubicles located in a larger open-plan office area that contained 12 to 22 workstations. At measurement sites in the occupied spaces, we monitored tracer gas concentrations at two heights above the floor, representing the breathing level of seated and standing adults, and at the nearest return air grille. $\mathrm{SF}_{6}$ concentrations were measured at least 20 times per nominal ventilation time constant using six gas analyzers that employ the photo-acoustic or nondispersive infrared methods. Multi-point sampling systems were used to collect data at up to three locations per gas analyzer. The analyzers were calibrated before and after the tests with multiple calibration gas standards.

Our prior laboratory based research indicates that the uncertainty in our measured values of ACE was approximately \pm 0.02 (Fisk et al. 1997). In field studies we anticipate a higher level of uncertainty. The ASHRAE Standard on measuring ACE (ASHRAE 2002) estimates that the maximum uncertainty in field-based measurements of ACE performed in accordance with the standard is \pm 0.16 .

\subsection{Pollutant removal efficiency for carbon dioxide}

The ACE indicates the efficiency of the ventilation process in controlling exposures to an indoor-generated pollutant emitted without momentum or buoyancy at locations spatially distributed within a building. The local pollutant removal efficiency (PRE) is a related parameter, but it indicates the efficiency of the ventilation process in controlling exposures to a real indoor pollutant which may have highly localized sources and be emitted with momentum, e.g., from a warm source. Thus, values of PRE can differ from values of ACE. Unfortunately, for most real pollutants measurements of PRE are impractical because of high measurement costs. However, it is practical to measure the PRE for $\mathrm{CO}_{2}$, which should be representative of the PRE for other occupant-generated pollutants. The local PRE for $\mathrm{CO}_{2}$ was calculated from the equation

$$
P R E_{\text {co } 2}=\Delta \overline{C_{R G}} / \Delta \overline{C_{b z}}
$$

where $\Delta \bar{C}$ equals the time-average difference between an indoor and outdoor work-day concentration of $\mathrm{CO}_{2}$, subscript "RG" refers to an indoor measurement at the return grille located nearest to the indoor measurement location, and subscript "bz" refers to an indoor measurement at a breathing zone height. We made separate $\mathrm{CO}_{2}$ measurements at the breathing height of seated 
and standing adults, 1.1 and $1.7 \mathrm{~m}$, respectively. Therefore, for each measurement site we calculated two corresponding values of local PRE, one based on $\mathrm{CO}_{2}$ measurements at seated breathing height and one based on $\mathrm{CO}_{2}$ measurements at standing breathing height - both calculations also used $\mathrm{CO}_{2}$ data from the nearest return grille. The reported values of PRE are 9 to 12-hour averages from the periods of occupancy of the office.

$\mathrm{CO}_{2}$ concentrations were measured and logged outdoors and at the same measurement sites where tracer gas concentrations were measured. Measurements were made using infrared $\mathrm{CO}_{2}$ analyzers calibrated at ten concentrations with gas standards. The calibration curve derived from the calibration data fit individual calibration data points within $\pm 3 \%$. Each analyzer had a multiplexing sample system, with concentration data obtained one minute out of every three at each measurement location. The errors in our reported values of PRE were greatly reduced by using the same instrument to measure $\mathrm{CO}_{2}$ at the return grill and breathing zone locations, the same instrument to measure all outdoor $\mathrm{CO}_{2}$ concentrations, and by averaging approximately 200 values of PRE measured at the same location each workday. Errors due to instrument bias were essentially eliminated, leaving errors due to measurement noise, which were reduced by averaging 200 measurements. As discussed by Fisk et al (2004), the estimated uncertainty in the average 200 values of PRE was $1.4 \%$.

\subsection{Thermal stratification and associated energy savings factors}

To quantify the extent of thermal stratification in the occupied spaces, air temperatures were measured and logged at seven heights $(0.1,0.6$, $1.1,1.7,2.0,2.2$, and $2.5 \mathrm{~m}$ ) above the floor near the six sites of tracer gas and $\mathrm{CO}_{2}$ monitoring. We also measured temperatures at ten locations in the supply air plenums beneath the suspended floors within $0.2 \mathrm{~m}$ of each vertical array of indoor air temperature sensors. The outputs of all temperature sensors were inter-compared immediately after the field study. Because we were interested in the extent of stratification, small differences in sensor calibration were important, therefore, we applied a correction factor to each sensor. After applying the correction factor, at normal room temperatures the readings of all sensors were within a $\pm 0.05{ }^{\circ} \mathrm{C}$ band; thus, the uncertainty in a calculated temperature difference is approximately $\pm 0.1{ }^{\circ} \mathrm{C}$.

As detailed in appendix 1 of Fisk et al (2004), vertical thermal stratification can reduce the energy consumed by air conditioning systems for sensible space cooling. The amount of energy needed to cool recirculated indoor air is unaffected by thermal stratification. However, the amount of energy needed for sensible cooling of incoming outdoor air can be reduced when there is temperature stratification in the building because the stratification enables a small increase in supply air temperature and corresponding increase in return air temperature. The amount of energy savings is proportional to the difference between the air temperature in the occupied zone $T_{O Z}$ and the air temperature of the return air $T_{R}$.

$$
\Delta T=T_{R}-T_{o z}
$$

For our analyses of study data, the value of $\mathrm{T}_{\mathrm{oz}}$ was based on the average of all temperature data collected between the heights of 0.1 and $1.7 \mathrm{~m}$. We calculated time-average values of $\Delta \mathrm{T}$.

The potential energy savings from thermal stratification were estimated from a savings fraction term $\left(\mathrm{SF}_{\mathrm{OA}}\right)$ which represents the reduction in sensible heat removal required of the air conditioner with thermal stratification divided by the sensible heat removal necessary to cool incoming outdoor air to the return air temperature. This metric is particularly relevant because it is the cooling loads for incoming outdoor air that are diminished by thermal stratification. The corresponding equation is

$$
S F_{O A}=\frac{M X \Delta T}{M X\left(T_{O A}-T_{R}\right)}
$$

where $\mathrm{M}$ equals the product of mass flow rate and specific heat of air flowing through the cooling coil; $\mathrm{X}$ is the fraction of outdoor air in the supply airstream, and $\mathrm{T}_{\mathrm{OA}}$ is the outdoor air temperature. 


\subsection{Occupant Survey}

All occupants were asked to complete a survey accessed via the Internet. The survey (Huizenga et al. 2003) collects background information on the respondents and their workspaces and asked the occupants to rate their level of satisfaction with office layout, furnishings, thermal comfort, air quality, lighting, acoustic quality, and cleanliness. In responses to core questions, the respondents indicate their level of satisfaction with a building condition on a seven-point scale, ranging from +3 representing very satisfied to -3 representing very dissatisfied, with a rating of zero indicating a neutral response. Figure 1 shows an example of a question. A special section of the survey asked about use of and satisfaction with the UFAD system. The responses from occupants in this study building were compared to average responses obtained from use of the survey in 67 buildings $^{2}$ - four with UFAD. Seventy eight percent of these buildings were located in the U.S., 79\% were government owned, $70 \%$ were offices, and $24 \%$ were courthouses. The confidentiality of respondents was maintained. The survey process was approved by the Committee for Protection of Human Subjects at the University of California, Berkeley.

How satisfied are you with the temperature in your workspace? Very Satisfied 0000000 Very Dissatisfied

Figure 1. Example survey question

\section{RESULTS}

\subsection{Environmental and Operating Conditions During Study}

Measurements were performed on four days in April of 2004. Between 7:00 and 11:00, supply air temperatures were sometimes higher than occupied space temperatures, indicating that spaces within the building were being heated. Measured two-hour average supply air temperatures during periods of space heating

\footnotetext{
${ }^{2}$ Includes the present study building
}

ranged from approximately 22.4 to $25.8{ }^{\circ} \mathrm{C}$. After $11: 00$ and at some locations before $11: 00$, supply air temperatures averaged over two-hour periods were lower than the occupied space temperatures, indicating that occupied spaces were being cooled. During cooling, two-hour average supply air temperatures were between approximately 21.7 and $23.9{ }^{\circ} \mathrm{C}$.

\subsection{Air Change Effectiveness (ACE)}

The measured values of ACE based on the average exhaust airstream age of air and the average of ages of air at the seated breathing level ranged from 0.90 to 1.03 and averaged 0.98 .

When instead we used the average ages of air at the breathing height of standing adults, the ACE ranged from 0.89 to 1.01 and averaged 0.96 . The 16 measured values of local ACE based on ages of air at return grilles and at the breathing height of seated workers ranged from 0.98 to 1.15 and averaged 1.04. The 16 measured values of local ACE based on ages of air at return grilles and at the breathing height of standing workers ranged from 0.98 to 1.10 and averaged 1.02. These ACE and local ACE values are not significantly different from unity given our estimated measurement uncertainty. Thus, the ACE in this building was indistinguishable from the ACE that would occur in a building with perfectly mixed indoor air.

\subsection{Pollutant removal efficiency}

Figure 2 illustrates the results of the PRE measurements. The 16 values of local PRE based on $\mathrm{CO}_{2}$ measurements at the seated breathing level height $(1.1 \mathrm{~m})$ and at the nearby return grille ranged from 1.03 to 1.32 and averaged 1.13. Considering our estimated measurement uncertainty of $1.4 \%$ for workday average values of PRE, the data indicate that the PRE for $\mathrm{CO}_{2}$ at the seated breathing height is significantly higher than in a space with well-mixed air, which would have a PRE of 1.0. The 16 measurements of local PRE based on measurements at the standing breathing level height $(1.7 \mathrm{~m})$ ranged from 0.92 to 1.24 and averaged 1.05. The elevation above unity of 0.05 only modestly exceeds our uncertainty estimate. Because most workers are seated, the PRE value of 1.13 is most relevant. 
One can estimate that concentrations of other occupant-generated pollutants at the inhalation zone are reduced by approximately $13 \%$ relative

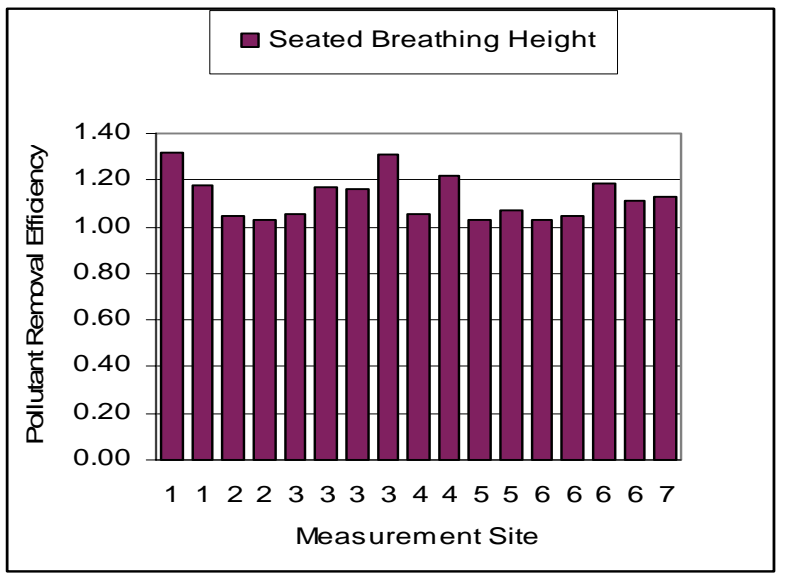

to an air distribution system that supplies the same amount of outdoor air and results in thorough mixing in rooms.

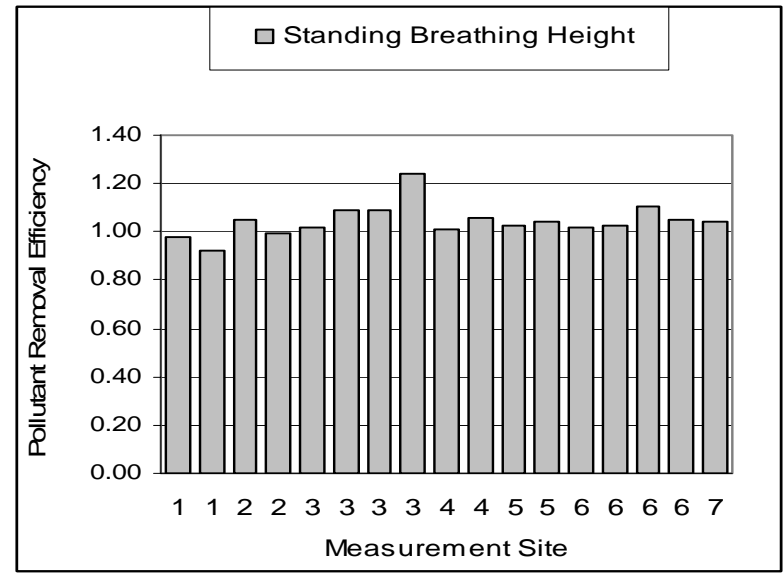

Figure 2. Measured values of pollutant removal efficiency (PRE) for carbon dioxide. With perfect mixing, the PRE would equal unity.

\subsection{Thermal stratification}

Figure 3 (left side) provides a typical example of the profile of air temperature with height, based on average temperatures for two-hour periods. In this figure, the temperatures at a height of $0 \mathrm{~m}$ represent the temperatures of the supply air. At this measurement site, between 7 and 9 am the space was being heated, thereafter it was being cooled. Temperatures increased $1{ }^{\circ} \mathrm{C}$ or less between heights of 0.1 and $3 \mathrm{~m}$. Figure 3 (right

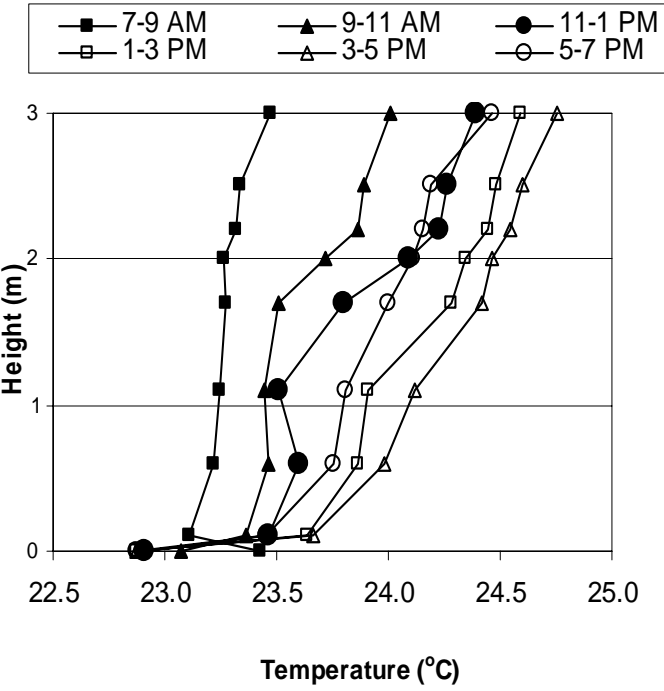

side) provides an example of the air temperature profile at the first floor cubicle location (measurement site 1) where temperatures increased by the largest amount with height. At this location, the air temperature increased approximately $2{ }^{\circ} \mathrm{C}$ between heights of 0.1 and 3 $\mathrm{m}$. The two sites had similar estimated thermal loads and supply flow rates. The average ceiling height was larger at the site with greater thermal stratification.

Figure 3. Examples of vertical temperature profiles.

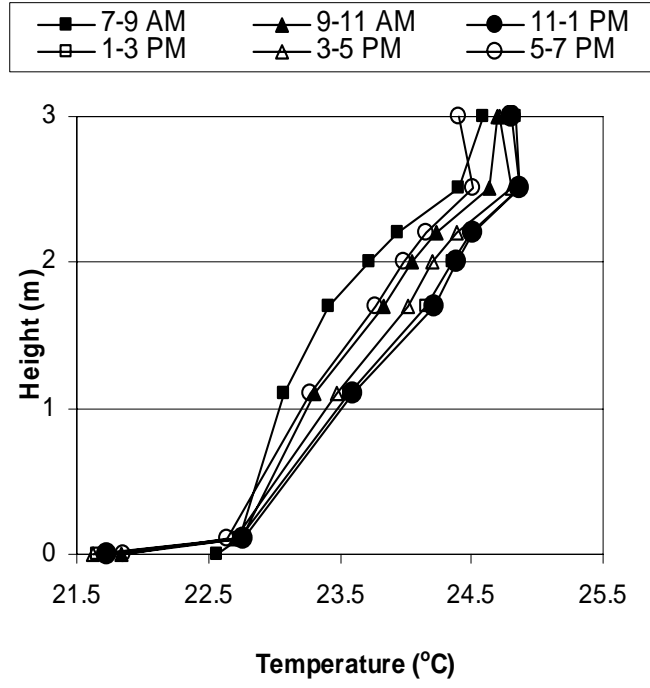


Table 2 indicates the degree of indoor temperature stratification and the heat removal effectiveness at each measurement site during periods of space cooling (after 11:00). The numbers in the table are time averages for all days of measurements. In absolute terms, the extent of temperature stratification was small, i.e., the air temperature at the return grille was less than $1{ }^{\circ} \mathrm{C}$ higher than the temperature just above the floor at a height of
$0.1 \mathrm{~m}$. However, during these measurements the temperature difference between the supply air and nearby return air grille averaged only 0.7 to 2.9 ${ }^{\circ} \mathrm{C}$; thus, it was not possible to have a large temperature stratification in the occupied space. The difference between return air temperature and average temperature in the occupied zone (see Equation 4) ranged from 0.5 to $1.2^{\circ} \mathrm{C}$ and averaged $0.7^{\circ} \mathrm{C}$.

Table 2. Vertical temperature stratification during periods of cooling (11:00 - 19:00)

\begin{tabular}{|c|c|c|c|c|c|c|}
\hline $\begin{array}{c}\text { Site } \\
\text { Code } \\
\#\end{array}$ & $\begin{array}{l}\text { Space } \\
\text { Type* }\end{array}$ & $\begin{array}{c}\text { Temp at Return } \\
\text { Grille } \\
\text { minus } \\
\text { Temp Supply } \\
\text { Air } \\
{ }^{0} \mathrm{C}\end{array}$ & $\begin{array}{c}\text { Temp at } \\
\text { Return Grille } \\
\text { minus } \\
\text { Temp at } 0.1 \mathrm{~m} \\
{ }^{0} \mathrm{C}\end{array}$ & $\begin{array}{c}\text { Temp at } 1.7 \mathrm{~m} \\
\text { minus } \\
\text { Temp at } 0.1 \mathrm{~m} \\
{ }^{0} \mathrm{C}\end{array}$ & \begin{tabular}{|} 
Temp at $1.1 \mathrm{~m}$ \\
minus \\
Temp at $0.1 \mathrm{~m}$ \\
${ }^{0} \mathrm{C}$
\end{tabular} & $\begin{array}{l}\text { Temp at Return } \\
\text { Grille divided by } \\
\text { average Temp in } \\
\text { occupied zone } \\
{ }^{\circ} \mathrm{C}\end{array}$ \\
\hline 1 & CS & 2.9 & 1.9 & 1.3 & 0.7 & 1.2 \\
\hline 2 & $\mathrm{PO}$ & 0.7 & 0.7 & 0.3 & 0.2 & 0.5 \\
\hline 3 & CS & 1.6 & 0.9 & 0.4 & 0.2 & 0.7 \\
\hline 4 & CS & 1.7 & 1.1 & 0.7 & 0.4 & 0.7 \\
\hline 5 & $\mathrm{PO}$ & 0.7 & 0.7 & 0.3 & 0.3 & 0.5 \\
\hline 6 & CS & 0.9 & 0.7 & 0.4 & 0.3 & 0.5 \\
\hline
\end{tabular}

* CS = cubicle space, $\mathrm{PO}$ = private office

\subsection{Survey Results}

The survey was made available to 95 workers and 45 (47\%) completed the survey. The response rate may have been diminished because many employees spent much of their work time away from the building. However it is near the $50 \%$ threshold considered appropriate for census surveys such as this one to reduce non-response bias to an acceptable rate (Hill et al. 1999). Seven percent of survey respondents were less than 30 years old, $62 \%$ had an age of 31 to 50 , and $31 \%$ were older than 50 . Sixty nine percent of survey respondents were male, $76 \%$ worked in cubicles, and 51\% worked more than 30 hours per week in their workspace.

Table 4 summarizes key results from the survey and provides data on building-mean survey responses from the reference population of 67 buildings. The respondents in the study building were most satisfied with office furnishings (comfort, adjustability, and color and texture), with thermal comfort, and with cleaning and maintenance. The level of satisfaction with lighting (amount and visual comfort) was particularly low, at the $8^{\text {th }}$ percentile, despite the attention to providing natural light in the building. The survey responses most likely to be affected by the UFAD system were thermal comfort and air quality. Thermal comfort ratings were substantially above average, at the $85^{\text {th }}$ percentile. Air quality ratings were slightly below average, at the $40^{\text {th }}$ percentile. However, many factors unrelated to the type of air distribution system may have influenced ratings of thermal comfort and air quality, for example air temperature setpoints and the strength of indoor air pollutant sources. Fifty seven percent of respondents indicated that they preferred the UFAD system to conventional overhead air distribution systems. 
Table 4. Key results of survey.

\begin{tabular}{|l|c|c|}
\hline \multicolumn{1}{|c|}{ Survey Questions } & $\begin{array}{c}\text { Reference } \\
\text { Buildings }\end{array}$ & \multicolumn{2}{c|}{ Study Building } \\
\cline { 2 - 4 } & $\begin{array}{c}\text { Mean } \\
\text { Response }\end{array}$ & $\begin{array}{c}\text { Mean } \\
\text { Response }\end{array}$ \\
Rank
\end{tabular}

*Reported satisfaction on a seven-point scale, ranging from +3 representing very satisfied to -3 representing very dissatisfied, with a rating of zero indicating a neutral response.

+The reported satisfaction ratings are averages from responses to two or three questions pertaining to the dimensions in parentheses.

\section{DISCUSSION}

\subsection{UFAD ventilation performance}

In our studies of this building with an UFAD system, the measured values of air change effectiveness (ACE) were very close to unity. In the U.S., the ACE is also normally very close to unity with traditional overhead air distribution systems (Fisk et al. 1992, 1997; Olesen and Seelen 1992; Persily 1986; Persily and Dols 1989). Thus, this study identified no significant improvement in ACE with UFAD. However, to the best of our knowledge, this is the first field study of ACE in a building with UFAD. With different UFAD equipment or different operating conditions, such as less air recirculation, it is possible that UFAD systems result in higher values of ACE. We estimated (Fisk et. al 2004) that the fraction of outdoor air in the supply airstream was approximately 0.2 in the east HVAC system and 0.4 in the west HVAC system, thus 60 to $80 \%$ of the supply air was recirculated indoor air. These recirculation rates, which are typical for U.S. buildings, could have prevented high values of ACE. Unfortunately, in the study building it was not possible to reduce the recirculation, and assess the effect on ACE.

The $\mathrm{CO}_{2}$ measurements indicated that the pollutant removal efficiency for $\mathrm{CO}_{2}$ was about $13 \%$ higher than expected in a building with thoroughly mixed indoor air. We would expect similar values of pollutant removal efficiency for other occupant-generated pollutants. These results suggest that the UFAD process reduced exposures to occupant-generated pollutants by roughly $13 \%$. However, we have no reference PRE data from buildings with typical overhead air distribution systems; hence, it is possible, that slightly elevated values of pollutant removal efficiency also occur in typical buildings.

The field study data (Fisk et al 2004) indicates that study building did have high rates of outdoor air supply per workstation, approximately three times the minimum rate specified per occupant in current ventilation standards (ASHRAE 2001). Despite the high rates of outdoor air supply, satisfaction with air quality was slightly below average ( $40^{\text {th }}$ percentile). We would not expect the rate of outdoor air supply to be a consistent predictor of satisfaction with air quality in 
individual buildings because other factors such as indoor pollutant generation rates also strongly affect air quality. However, from studies of large sets of buildings, on average, the satisfaction with air quality has improved with an increased outdoor air supply rate (Seppanen et al. 1999).

\subsection{Temperature stratification and implications for energy savings}

The measured increase in indoor temperature between locations just above the floor and the return air grilles was small, always less than 1.9 ${ }^{\circ} \mathrm{C}$. The combination of low internal thermal loads and moderate supply air flow rates in the study building were such that one could not expect a large amount of vertical thermal stratification. Therefore, it is possible that more thermal stratification would have occurred, as observed in controlled laboratory studies (Webster et al. 2002), if supply air flow rates were lower or internal heat generation rates were increased. For example, more thermal stratification would be expected if the building had full occupancy (more heat loads) or had a variable air volume ventilation system that automatically reduced supply flow rates when the demand for cooling was low.

Although the magnitude of temperature stratification was small, the results indicate a potential for energy savings during periods of air conditioning. To estimate the potential energy savings, we can apply equation 5 using examples of the temperatures and outdoor air fraction encountered during periods of air conditioning. For these example calculations, we assume $\mathrm{T}_{\mathrm{OA}}$, $\mathrm{T}_{\mathrm{R}}$, and $\mathrm{X}$ equal $33{ }^{\circ} \mathrm{C}, 25{ }^{\circ} \mathrm{C}$, and 0.3 , respectively. With these assumptions, each $1{ }^{\circ} \mathrm{C}$ difference between $\mathrm{T}_{\mathrm{R}}$ and $\mathrm{T}_{\mathrm{OZ}}$ corresponds to a $11 \%$ reduction in the energy required for the sensible cooling of incoming outdoor air $\left(\mathrm{SF}_{\mathrm{OA}}\right)$.

If a building is being heated with warmed supply air, thermal stratification will increase the heating energy use because it increases the temperature, hence the energy content, of air exhausted to outdoors by the HVAC system. However, from a consideration of basic fluid dynamics we would expect heating of a building with a UFAD system to cause less thermal stratification than heating of a building with a conventional air distribution system that supplies and removes warm air at the ceiling. Thus, UFAD systems may also reduce heating energy consumption; however, measurements of temperature gradients under conditions with heating are necessary before any conclusions are drawn.

We caution that the temperature stratification data from this study need to be confirmed in other studies performed in buildings with UFAD, both with similar and with other operating conditions. The present results were based on data from one building with very limited variability in operating conditions.

\subsection{Survey results}

Based on the survey, the occupant's level of satisfaction with most characteristics of the building was comparable to mean level of satisfaction of occupants in reference buildings. The level of satisfaction with thermal comfort was at the $85^{\text {th }}$ percentile, and this high satisfaction rating could possibly be due, in all or part, to the use of a UFAD system. However, the percentile ranks of thermal comfort ratings from four UFAD buildings that have completed the survey have varied considerably $\left(95 \%, 36 \%{ }^{3}, 85 \%\right.$, 48\%), with a mean percentile rank of $66 \%$. Therefore, in this very small sample, the level of thermal comfort in UFAD buildings was only moderately superior to the average level of thermal comfort in conventional buildings. The low satisfaction rating for lighting, at the $8^{\text {th }}$ percentile, was the most striking finding from the survey; however, the presence or absence of UFAD does not likely affect satisfaction with lighting. The occupants who were dissatisfied with lighting reported that it was too dark (82\%), that there was not enough daylight (59\%), and that there was not enough electric lighting (68\%). While the web-based survey was easy to use and very informative, the current reference database was modest in size. Ideally, one would compare the survey responses from this study building to responses from a large number of similar size, similar age office buildings located in the U.S. Ideally, the

\footnotetext{
${ }^{3}$ Average from two surveys in the same building that yielded the same percentile rank within $1 \%$.
} 
comparison would also control for personal factors such as job type, gender, and age of respondents.

The major limitations of this study were that it examined the performance of a single building with UFAD and that HVAC operating conditions could not be modified. Thus, we caution against drawing general conclusions about UFAD based on this study. This study did provide unique data suitable for characterizing several aspects of UFAD performance in the study building and provides some evidence of benefits of UFAD that need to be confirmed in other studies. The study also provides a methodology for use in future field studies of UFAD systems.

\section{CONCLUSIONS}

In the study building:

- The air change effectiveness was very close to unity, which is the value typically observed with conventional overhead air supply systems. Thus, the study did not identify an opportunity to save energy by reducing the rate of outdoor air supply because of a high value of air change effectiveness.

- The pollutant removal efficiency for carbon dioxide was 13\% higher that expected with perfectly mixed indoor air, suggesting a $13 \%$ reduction in exposures to occupant generated pollutants.

- The increase in air temperature from locations just above the floor to return grilles was 1 to 2 ${ }^{\circ} \mathrm{C}$. This amount of thermal stratification could reduce the sensible energy requirements for cooling of outdoor air by approximately $10 \%$.

- The occupants' level of satisfaction with thermal conditions was well above average. This high satisfaction rating could possibly be due, in all or part, to the use of a UFAD system.

The results of this study provide some evidence of energy and IAQ-related benefits of UFAD. Before general conclusions are drawn, the benefits need to be confirmed in other studies.

\section{ACKNOWLEDGMENTS}

This work was supported by the Assistant Secretary for Energy Efficiency and Renewable Energy, Building Technology Program of the U.S. Department of Energy under contract DE-AC0376SF00098. We thank Ketakee Kane for her assistance in the data analysis and Fred Bauman and Woody Delp for reviewing a draft of this paper.

\section{REFERENCES}

ASHRAE (2002) Measuring air change effectiveness: ANSI/ASHRAE Standard 1291997, RA 2002). American Society of Heating, Refrigerating, and Air Conditioning Engineers. Atlanta

ASHRAE (2001) Ventilation for Acceptable Indoor Air Quality, ANSI/ASHRAE Standard 622001. American Society of Heating, Refrigerating, and Air Conditioning Engineers. Atlanta

Bauman F. (2003). Underfloor Air Distribution Design Guide. Atlanta: American Society of Heating, Refrigerating, and Air-Conditioning Engineers, Inc., Atlanta.

Bauman F and T. Webster T (2001) Outlook for Underfloor Air Distribution. ASHRAE Journal June 2001, pp. 18-25.

Faulkner, D., Fisk, W.J., and Sullivan, D.P. (1993) "Indoor Airflow and Pollutant Removal in a Room With Floor-Based Task Ventilation: Results of Additional Experiments", Building and Environment 30(3), pp. 323-332.

Fisk, WJ and Faulkner, D. 1992. Air Exchange Effectiveness in Office Buildings: Measurement Techniques and Results, Proceedings of the 1992 International Symposium on Room Air Convection and Ventilation Effectiveness, July 22-24, Tokyo, pp. 213-223, published by ASHRAE, Atlanta. 
Fisk, WJ, Faulkner, D, Sullivan, DP, and Bauman, FS. 1997. Air Change Effectiveness and Pollutant Removal Efficiency During Adverse Mixing Conditions, Indoor Air 7(1): 55-63.

Fisk WJ, Faulkner D, Sullivan D, Chao C, Wan MP, Zagreus L, and Webster T (2004) Performance of Underfloor Air Distribution: Results of a Field Study. Lawrence Berkeley National Laboratory Report, Berkeley, CA LBNL-56257.

Hill, N., Brierley, J., and MacDougall R. (1999) How to Measure Customer Satisfaction, Gower Publishing Ltd.

Huizenga C, Zagreus L, Arens E and Lehrer, D (2003) Measuring Indoor Environmental Quality: A Web-based Occupant Satisfaction Survey. Proceedings of the Greenbuild 2003 Conference, Pittsburgh, PA.

http://www.cbe.berkeley.edu/underfloorair/moreI nfo.htm

Lehrer, D. and F. Bauman, 2003. Hype vs. Reality: New Research Findings on Underfloor Air Distribution Systems. Proceedings of the Greenbuild 2003 Conference, Pittsburgh PA. http://www.cbe.berkeley.edu/underfloorair/moreI nfo.htm

Olesen, BW and Seelen, J. 1992. Field Measurements of Air Change Effectiveness using Tracer Gas Techniques, Proceedings of IAQ'92, Environments for People, pp. 301-308, Published by ASHRAE, Atlanta.

Persily, AK. 1986. Ventilation Effectiveness Measurements in an Office Building, Proceedings of IAQ'86, Managing Indoor Air for Health and Energy Conservation, pp. 548-567. Published by ASHRAE, Atlanta.

Persily, AK and Dols, WS. (1989) "Field Measurements of Ventilation and Ventilation Effectiveness in an Office/Library Building”, Indoor Air 1(3): 229-246.

Seppanen, O.A., Fisk, W.J., and Mendell, M.J. (1999) Association of Ventilation Rates and CO2 Concentrations with Health and other Human
Responses in Commercial and Institutional Buildings. Indoor Air 9: 226-252.

Webster TL, Bauman FS, Reese J and Shi M (2002). Thermal Stratification Performance of Underfloor Air Distribution (UFAD) Systems. Proceedings of the Indoor Air 2002 Conference, vol. 4, pp 260-265. Indoor Air 2002, Inc, Santa Cruz, CA, 